\title{
A Study of the Relationship between Iranian Learners' Sociocultural Identity and English as a Foreign Language (EFL) Learning Proficiency
}

\section{Habib Mohammadi}

Department of English Language Teaching, Zanjan Branch, Islamic Azad University, Zanjan, Iran, habib.mohammadi632@gmail.com

\section{Siros Izadpanah}

Asst. Prof., corresponding author, Department of English Language Teaching, Zanjan Branch, Islamic Azad University, Zanjan, Iran, cyrosIzadpanah@yahoo.com

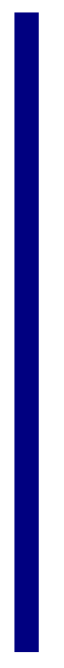

\begin{abstract}
Due to the development of English as an international language and dominance of fever of it, researchers were interested in the influential factors in learning English as a foreign or second language, and their relationship with English learning, such as; gender, different kinds of identity, religion, and etc. However, there are few studies on the relationship between sociocultural identity and EFL learning. This study aimed to investigate the relationship between Iranian learners' sociocultural identity and their EFL learning. In this correlational study, 360 intermediate and advanced English students from four institutes in Zanjan Province, Iran, were selected based on the cluster sampling method. The Oxford Quick Placement Test was used to check the EFL learning proficiency and make homogeneous groups. Aspects of Identity Questionnaire Cheek (2013) was utilized to check the level of learners' sociocultural identity. The normality of data was checked based on Skewness and Kurtosis normal test, therefore, Pearson Correlation Coefficient was applied in this study. The result has indicated that there was a negative significant (-678) relationship between learners' sociocultural identity and their EFL learning. This finding will be beneficial for syllabus designers, language learners, their parents, and language teachers.
\end{abstract}

Keywords: EFL learning proficiency, identity, language learning, sociocultural identity, English language

\section{INTRODUCTION}

Due to development of technology and discourse of English as a global language and the needs for close interaction between people around the world, English, the language of dominant countries has been introduced as an international language to be used inter nations (Moser, Zhu, Nguyen, \& Williams, 2018; Yuen, \& Hew, 2018). As Pan and

Citation: Mohammadi, H., \& Izadpanah, S. (2019). A Study of the Relationship between Iranian Learners' Sociocultural Identity and English as a Foreign Language (EFL) Learning Proficiency. International Journal of Instruction, 12(1), 53-68. https://doi.org/10.29333/iji.2019.1214a 
Block, (2011) claim in order to be able to communicate in a globalized world, people should not stick to one language. People need to learn this international language to be able to communicate with others from different countries (Achugar, \& Carpenter, 2018). But EFL learning is dependent on some prerequisite influential factors such as motivation and attitude (Achugar, \& Carpenter, 2018). Learners should be motivated and have positive attitudes towards learning foreign language (Dávila, 2017; Moser, Zhu, Nguyen, \& Williams, 2018). In spite of major research has been done in the field of identity and learning a language, a major gap can be seen in the area of relationship between sociocultural identity and foreign language learning. Most of the previous studies investigated the impact of different parts of identity on learning a second or foreign language (e.g. religion identity, social identity, cultural identity, self-identity, etc.). Also, some others concentrated on the impact of teachers' identity on their teaching performance. Some investigated the relationship between different types of identity with EFL learning. Some studies explored these issues in the field of English speaking countries with immigrants (e.g. Machado-Casas, 2012). There were some studies in Iran with the aim of finding relationship between identity and EFL learning. For example, Mostafaei, Alaei, and Ghamari, (2013) studied the relationship between national identity and EFL learning, and Zare-ee. and Asgari Matin. (2014) examined the relationship between self- identity and EFL learning. However, the relationship between sociocultural identity and EFL learning was not investigated in Iranian multilingual situation like Zanjan Province.

English learning in Iran, with the specific sociocultural characteristics is more challenging issue. Having specific culture, religion and political conflict with western English speaking countries on one side and the need for learning international language on the other side, has caused Iran to have particular situation for EFL learning. Therefore, there is a crucial need for more research that examines the issues of language and identity in the complex and various linguistic contexts in Iran. English is a foreign language, but it is seen as an important tool to help the nation grow towards achieving its goal of becoming a progressed nation. It is suggested that there is a need for more investigation of its role in identity formation and the role of sociocultural identity on English language learning and English speaking proficiency. The purpose of this article was to investigate the relationship between Iranian learners' sociocultural identity and their level of EFL learning proficiency. Moreover, it aims to answer the research question and prove the research hypothesis.

\section{LITERATURE REVIEW}

\section{Theoretical Background}

According to Longman Dictionary of language teaching and applied linguistics (Richards \& Schmidt, 2013) identity is defined as: "a person's sense of themselves as a discrete, separate individual, including their self-image and their awareness of self, and an important concept in sociocultural theory. People's sense of identity influences how they view themselves both as an individual and in relation to other people (White, Stackhouse, \& Argo, 2018). The term "sociocultural identity" comprises three concepts: society, culture, and identity (Orsini-Jones, \& Lee, 2018). A society is a number of 
interdependent associations of the same species. A culture is the acquired behaviours that are shared by the members of a society, together with the material products of such behaviour. The words "society" and "culture" are fused together to form the word "sociocultural". Sociocultural identity comprises different parts of identities; social identity, cultural identity, religious identity, ethnic identity, and so on (Miller, Berlo, Wolf, \& Roberts, 2018). Iran has a religious society. Also, there is a political problem between Iran and English speaking countries. Therefore, Iranian society and culture are affected by political issue, religion and history. Learning a new language, as a part of society, in Islamic Republic of Iran is affected by this sociocultural identity.

\section{Related Studies on Language and Identity}

Behtash, Hashemi, and Farokhipour (2017) conducted a study to investigate any possible effect of religious identity on language learning in Iran, they tried to shed light on the relationship between religious identities and learning cultural aspects of English as a foreign language among Iranian advanced language learners. The data were gathered by two main instruments. The first instrument was a measure of religious identity developed by Khodayarifard (2003) and the second instrument used in this study was a culture learning test developed by the researchers based on Ward and RanaDeuba (1999) culture learning scale. Twenty-nine male students, studying English as a foreign language in a language learning institute in Iran, participated in this study. The data were analyzed by Pearson product-moment correlation and the result showed that there was a significant, negative correlation between these two variables.

Grey and van Hell, (2017) conducted a study on the effect of foreign-accented speaker identity on the language processing. Data were gathered by behavioural measures of sentence comprehension, language attitudes, and accent perception. The result of these sets of data gathering methods showed the accuracy of listeners in grammatical, listening and speaking process. Only some violations were elicited in semantic comprehending. Accordingly, the result indicates a great deal of native-like speaking identity on language learning process.

Zhou, (2016) examined the different motivational attitude among Chinese English as a Second Language (ESL) students with different level of reading proficiency. The aim of this research was assessed by two essential elements _ learners' motivation and their language identity _ that influence their attitudes and learning outcome. The sample size for this study was originally designed to include 33 Chinese ESL students from the different level at the English Language Center of a university in southern Ontario, Canada. They divided into two groups based on the International English Language Testing System (IELTS). Participants who got 6.0 or less placed in a low level and who had 6.5 or more placed in high- level group. A mixed design was applied for collecting data. The quantitative approach was used to examine the relationship between reading proficiency and learners' motivation for Reading in English. The quantitative data were analyzed by scientific Statistical Package for the Social Science (SPSS) 24.

Altugan (2015) conducted a qualitative and descriptive study and stated that combining cultural identity into learning is a controversial task because identity construction is a 
kind of complex process and is gradually attained in social surroundings. He also argued that cultural backgrounds of learners are significant because the diversity of influential factors on identity (i.e. ethnic, racial, linguistic, social, religious or economic differences) can cause cultural detachment and demotivating to learning. Thus, he investigated the relationship between learning and cultural identity. He revealed that there is a positive correlation between the two.

In the field of the impact of cultural identity on learning foreign language pronunciation, Bazrafshan. (2015) conducted a study in Iranian context to investigate the types of motivation and the impact of cultural identity on language pronunciation.

Sixty Iranian EFL high school boys and girls in Sabzevar, in the range of 16 to 18 years old, were selected by convenience non-random sampling procedure and answered the Language Learning Attitude Questionnaire (LLAQ) and the Cultural Identity Questionnaire in order to measure their attitudes and cultural identity about English language pronunciation.

The result indicated that cultural identity had a meaningful negative correlation with learning pronunciation among the Iranian EFL students. It showed that cultural identity affects pronunciation learning. This study investigated one aspect of the relationship between identity and learning a language. In this study, the impact of identity on getting language pronunciation was examined.

In one related study, Zeinivand, Azizifar, \& Gowhary, (2015) investigated the correlation between attitude and speaking proficiency in the Iranian EFL context. For this study, the sample included 70 EFL learners from three Institutions in the city of Darrehshahr. The Data were collected through using Gardner's Attitude/Motivation Test Battery Questionnaire and speaking Proficiency Test to measure the English speaking proficiency level. The result revealed that EFL learners have a very high attitude towards learning English and relationship between attitude and speaking proficiency learners were positive. Since identity is considered as an influential factor in learners' attitude, it can be argued that the higher the learners' identity level, the less attitude they have to English learning and speaking. Therefore, the relationship between identity and level of speaking proficiency was negative in the study.

In an investigation into the effect of ego identity on the language competency of the learners, Tavakoli, Rakhshanderoo, Izadpanah, and Moradi, (2014) conducted a research in the Iranian context. In this study, they tried to find out which identity types cause higher levels of language proficiency? To do this end, 98 male and female learners studying English at Soha and Bahar language institutes in Shiraz, participated and answered Ego Identity Process Questionnaires with 32 items to check the ego identity, and the Oxford Placement Test, version 1, to check the level of learning proficiency. The results of the study showed that the achieved ego identity type had a better impact on language learning.

The study tried to compare different types of identity and their effect on language learning. Therefore, different identities were examined in term of language learning. They found that there is a significant effect of learning a new language on learners' identity. 


\section{RESEARCH QUESTION AND HYPOTHESIS}

RQ: Is there any statistically significant relationship between Iranian learners' sociocultural identity and their level of EFL learning proficiency?

H1: There is a negative relationship between Iranian learners' sociocultural identity and their EFL learning proficiency.

\section{METHOD}

\section{Design of the Study}

The descriptive correlational study was utilized in this research to examine the function of learners' sociocultural identity on EFL learning proficiency. To this end, Quantitative Aspect of Identity Questionnaire was used to check the level of learners' sociocultural identity, and Oxford Quick Placement Test was administered to check the level of EFL learning proficiency. The relationship between the variables was checked by SPSS,18. Different parts of methodology will be discussed below.

\section{Participants}

The participants of this study were 360 English learners within the age range of 14 to 35 who have been studying at an intermediate and advanced level in six English institutes in Zanjan and Tarom, Iran. They were selected through the cluster sampling. In a way that, from all institutes located in Zanjan and Tarom, $(n=110)$ six institutes were randomly selected, two were from Tarom and four were from Zanjan. According to the informatics statistic of educational office of Zanjan province, the whole population of this study were 19400 males and females English learners in 110 institutes located in Zanjan and Tarom who were studying in English courses in summer semester in 2017. According to the information that has been obtained from institutes, nearly $30 \%$ of learners were studying at the level of intermediate and advanced $(n=5820)$. From this number, there were 3492 girls and 2328 males. According to Morgan's table $(95 \%$ confidence \& $5.0 \%$ error), 360 English learners were needed for this study as a sample size (216 females \& 144 males). In order to find this sample size, six institutes in Zanjan and Tarom were selected. Four institutes in Zanjan (Goyesh institute 1 for boys \& Goyesh institute for girls; Safir for girls, \& Goyesh 2 for boys) and two from Tarom (Bayan institute for boys \& Sogand institute for girls).The entire students in these six institutes were 1340 students in summer 2017. Four classes in the level of intermediate and advanced (according to the institutes' placement) were selected from each institution. As a result, we had 24 classes, twelve boy classes and twelve girl classes. The whole number of students in these 24 classes was 152 males and 228 females, but we needed 216 females and 144 males. Thus, to select the population for this study and to have the homogenous groups, the Oxford Quick Placement Test was administered to these 24 classes. As a result, 216 females and 144 males were selected for this study. Those learners who did not complete the test completely or could not reach the required score were discarded and consequently, 20 of the participants were omitted from this study. 
Also, they were divided into two groups. Group A as an advanced level (48 males, \& 72 females) and group B as an intermediate (96 males, \& 144 females). Students, who could answer 28 to 36 questions out of 60 of the Oxford Quick Placement Test, were selected as an intermediate, and those who could answer 48 to 55 questions were selected as an advanced level of proficiency.

To avoid the effect of the demographic feature of age, all the participants aged in the range of 14 to 35 were selected for this study, since kids' (up to 14 years old) identity has not been shaped yet and adults' (over 35) identity has been completely formed. Students' native language was Persian and Azeri in Zanjan. English was the second or third language of them.

\section{Instruments}

In the present study, one written questionnaire and one placement test were utilized.

1) Oxford Quick Placement Test:

To elicit the information about learners' proficiency level, and to get the homogenous group, Oxford Quick Placement Test (2007) with 60 items in Likert scale was applied. The test was used with no change and indicated scores between 1 and 60 in scale. For this study in order to have the homogeneous groups, the researchers chose participants lower intermediate and advanced level based on the following rating method; 28-36 Lower-intermediate 48-55 Advanced

2) Aspect of Identity Questionnaire:

For investigating the role of learners' sociocultural identity on learning English as a foreign language, and to check the strength and weakness of learners' general identity, Aspect of Identity Questionnaire (AIQ-IV) Cheek and Briggs, (2013) was applied.

\section{Procedure}

The researchers initially contacted with the managers of institutes to ask if we were welcome to do the study in their institutes. After receiving their approval, the researchers started the process of recruiting participants. Initially, the Oxford Quick Placement Test was administered to check the students' level of proficiency. Using the result of this placement test, researchers divided them into the intermediate and advanced level of English language proficiency. Those who could answer at least 28 to 36 questions, placed in the intermediate level and those who could answer 48 to 55 questions out of 60 questions placed in advance. As a result, 360 students were selected. Among these, there were 144 males and 216 females. A week later Aspect of Identity Questionnaire (Cheek \& Briggs, 2013) was administered to check the level of learners' sociocultural identity. The correlation of this questionnaire with a proficiency test was analyzed by Pearson Correlation Coefficient Test, Statistical Package for the Social Science (SPSS) 18.

\section{Reliability of the Questionnaires}

The issue of reliability was mostly equal to consistency. To check the reliability of instruments, Cronbach's coefficient alpha was used. Usually, in terms of reliability by 
Cronbach's coefficient alpha, estimated coefficient alpha under $60 \%$ is considered weak, and consistency estimated to $70 \%$ is acceptable, and over $80 \%$ is considered good (Danaeifard, Khaef Elahi, \& Hosseini, (2011). In the present study, the reliability coefficient of the questionnaires (0.977) was found very well.

The instruments used in this study were already reliable by authors; however, after collecting data, the coefficient alpha of variables was calculated. The scale scores of Cronbach's coefficient alpha for the variables of Sociocultural Identity (0.832), Oxford University Test for learning proficiency (0.72), was determined (Table 1). According to the table (1) obtained coefficient alpha for variables and the instruments were over $70 \%$. Consequently, it can be claimed that the questionnaire and test of the present study were of applicable reliability.

Table 1

Cronbach's Coefficient Alpha for Questionnaires

\begin{tabular}{llll}
\hline variables & $\begin{array}{l}\text { Number of questions } \\
\text { item }\end{array}$ & Participants & Cronbach's coefficient alpha \\
\hline Sociocultural identity & 45 & 360 & $0 / 832$ \\
\hline $\begin{array}{l}\text { Oxford placement } \\
\text { test(English learning) }\end{array}$ & 60 & 360 & $0 / 720$ \\
\hline
\end{tabular}

\section{Backward and Forward Translation}

After getting the permission from the developers of the questionnaires to translate and apply them, the following was done based on the Beitone method in 6 stages:

First stage: Persian translation

The first stage in adaptation is the forward translation. The original English version of the questionnaire is translated from English to Farsi by two experts fluent in Persian and English simultaneously. The two translators should have different, backgrounds. To improve the quality of the translation, and matching meanings of translated words with language learning, one of the translators was informed about the aim of the study, and the other one was not informed about the goal. Translators were asked to avoid word by word translation.

\section{Second stage: Combination of The Translations}

Two translators together with researcher compared and reviewed both the Persian translated version and original version word by word in terms of general terms, use of understandable words and avoiding the use of specialized words. In the process of reviewing and revising, minor corrections have been made to translation. Finally, after solving problems and cultural adaptation of meanings of sentences, a copy of Persian translation was provided.

\section{Third stage: Back Translation}

In this stage, two other translators of native English speaker, with non-English training background who were fluent in Persian language were selected to back translate to the 
original language. They did not access the original version of questionnaires. In this way, two written documents of English translated from each questionnaire were prepared.

\section{Fourth stage: Expert Commission}

Matching English and Persian translation by the researcher. In this stage in order to reach the final conclusion, all translated versions in English and Persian as well as an original language version, were revised one more time. Finally, for greater assurance in terms of semantic equivalence, replacing Expressions Equivalent, cultural and social correspondence, existing grammar and spelling errors in translation and back translation and the degree of equivalence with the original version, was done under the supervision of the group of translators, supervisor, and researcher.

\section{Validation}

One of the main characteristics of any instruments is validity. In order to have appropriate validity for applied questionnaires and consequently to have an appropriate result, the researcher should validate them. The utilized questionnaire and test in this research have already been validated by authors (as explained in part 3-4). Moreover, the researcher had three experts idea about the appropriateness of the instruments to be used in the present study.

\section{Data Analysis}

The raw data were written into the computer and then analyzed using SPSS software (version 18). First of all the descriptive statistics of variables (frequency, percentile, mean, and SD) were analyzed to check the demographic features of variables.

Reliability was calculated by utilizing Cronbach's Coefficient Alpha. Afterward, the normality of collected data was examined by Skewness and Kurtosis values, to identify the appropriate method (parametric or non-parametric) for analyzing data. Since the result indicated that the data were normal, in inferential statistics Pearson correlation coefficient was used to analyze the research questions and hypothesis.

To check the hypothesis and research question, and to see any association between sociocultural identity items and EFL learning proficiency, Pearson correlation analysis was carried out to examine the significance of socio-cultural identity on investment in EFL learning proficiency. English learning proficiency Regression Model based on the independent variable of sociocultural identity was formed. Consequently, the equation model for the hypothesis was shaped.

\section{FINDINGS}

\section{Descriptive Findings Related to Demographic Variables:}

These findings are some of the individual characteristics of participants that are represented in tables 2 to 3 . Table 2 reported the distribution of subjects in terms of gender. 
Table2

The Distribution of Participants' Gender

\begin{tabular}{clllll}
\hline Gender & & Frequency & Percent & Valid Percent & Cumulative Percent \\
\hline Female & 216 & 60.0 & 60.0 & 60.0 \\
\cline { 2 - 6 } & Male & 144 & 40.0 & 40.0 & 100.0 \\
\cline { 2 - 5 } & Total & 360 & 100.0 & 100.0 & \\
\hline
\end{tabular}

In this study, the participants included both genders. As represented in table 2, male participants 40 percent and female participants account for 60 percent of the sample size. Table 3, displays the distribution of subjects is based on age group.

Table 3

The Distribution of Subjects is Based on Age Groups.

\begin{tabular}{lllll}
\hline Age & Frequency & Percent & Valid Percent & Cumulative Percent \\
\hline $14-18$ & 85 & 23.6 & 23.6 & 23.6 \\
\hline $19-23$ & 27 & 7.5 & 7.5 & 31.1 \\
\hline $24-28$ & 65 & 18.1 & 18.1 & 49.2 \\
\hline $29-33$ & 51 & 14.2 & 14.2 & 63.3 \\
\hline $34-35$ & 132 & 36.7 & 36.7 & 100.0 \\
\hline Total & 360 & 100.0 & 100.0 & \\
\hline
\end{tabular}

As we can see in table 3, subjects aged 34- 35, with $36.67 \%$ of all participants, comprise the most frequent and those subjects aged 19-23 with about $40.5 \%$, constitute the least frequent subjects. According to this table, the participants were selected in the age range of 14- 35. Since the children's identity is not formed and elderlies' identity is totally fixed, we selected participants in this age range.

\section{Descriptive Findings Related to Variables}

Table 4, represents the descriptive statistics of mean, the Standard Deviation (SD), the Minimum and a Maximum score of participants in variables.

Table 4

Mean, S D, Minimum \& Maximum scores in variables

\begin{tabular}{|c|c|c|c|c|c|}
\hline $\begin{array}{l}\text { Statistical indicators } \\
\text { Variables }\end{array}$ & $\mathrm{N}$ & Minimum & Maximum & Mean & Std. Deviation \\
\hline Sociocultural Identity & 360 & 2.64 & 4.58 & 3.1590 & .35968 \\
\hline EFL proficiency & 360 & 34.00 & 60.00 & 51.0750 & 5.07958 \\
\hline
\end{tabular}

\section{Normal Distribution Test of Variables}

The normal distribution assumption was examined to support in selecting statistical tests for variable analyses. To select a right test to analyze the hypothesis, first, you need to ensure the statistical distribution of the variable tested. In the other word, the normal distribution of statistical variables should be considered.

To check the statistical distribution of variables, the test that is known as NikoeiBarazesh was utilized, that one way to check the normal distribution is the Skewness 
and Kurtosis values. Normally the Skewness and Kurtosis values lie in the range of (-2, 2 ). If they were not in this range, the gathered data were out of normality. Accordingly, the normal distribution assumption test was applied in the present study.

Table 5

Normal Test of the Distribution of the Data

\begin{tabular}{llllll}
\hline & $\mathrm{N}$ & Skewness & Kurtosis & \\
\cline { 2 - 6 } & Statistic & Statistic & Std. Error & Statistic & Std. Error \\
\hline Sociocultural identity & 360 & .619 & .129 & -.612 & .256 \\
\hline EFL proficiency & 360 & -.362 & .129 & -.307 & .256 \\
\hline
\end{tabular}

According to the result of the distribution represented in table 5, the value of the skewness observed with the sociocultural identity variable is equal to .619 which was within the normal range of $(-2,2)$. And it was suggested that the variable Sociocultural Identity skewness was normally distributed.

The Kurtosis value of this variable was -612 that was in the normal range of $(-2,2)$. It indicated that this variable was normally distributed. The Skewness value of EFL proficiency was -.362 that was in the normal range of $(-2,2)$. It indicated that this variable was normally distributed. The Kurtosis value of this was -.307 that was in the normal range of $(-2,2)$. It indicated that this variable was normally distributed.

\section{Findings Related to the Testing of Research Hypothesis}

This study was conducted to investigate the following hypothesis:

H1: There is a relationship between sociocultural identity and EFL learning proficiency.

\section{Data Analysis of the Hypothesis and Research Question}

The research question was about the relationship between sociocultural identity and EFL learning proficiency. Our hypothesized was that "there is a significant relationship between learners' sociocultural identity and their English as a foreign language (EFL) learning proficiency." As indicated in table 6, Pearson correlation test was applied to check this relationship.

Table 6

Pearson Correlation Coefficient Between Sociocultural Identity and EFL Learning Proficiency

\begin{tabular}{rrrrr}
$\begin{array}{r}\text { Independent } \\
\text { variable }\end{array}$ & Dependent variable & $\begin{array}{r}(\mathrm{r}) \\
\text { Correlation Coefficient }\end{array}$ & $\begin{array}{r}\text { Sig } \\
(\mathrm{p})\end{array}$ & Result \\
\hline $\begin{array}{l}\text { Sociocultural } \\
\text { Identity }\end{array}$ & Learning English & $-.678^{* * *}$ & .001 & Confirmed \\
\hline
\end{tabular}

As suggested by the hypothesis, there is a relationship between sociocultural identity and English learning proficiency. Finding of this table proved this relationship in the

level of $(\alpha=0 / 01)$. 
Since the obtained Sig in this test is equal to ( $\mathrm{Sig}=0 / 001)$, and correlation coefficient (678 ) the relationship between two variables is statistically significant and negative.

Accordingly, the null hypothesis, pointing to no relationship, was rejected, meaning statistically, there was a significant negative relationship between sociocultural identity and EFL learning proficiency. And the hypothesis is confirmed.

The level of sociocultural identity to be higher, the level of English language learning will be difficult. In other word, learners' sociocultural identity has a big impact on EFL learning. This finding suggested that by increasing a single unit in the level of sociocultural identity, EFL learners will be demotivated. And English learning proficiency will be decreased up to $(-67 \%)$.

\section{DISCUSSION}

As Tseng (2002) stated it is obvious that there is a link between learning and identity. . Their relationship is twofold. Learners' identities affect learning, specially learning language, and on the other hand, learning influences the learners' identity.

The main focus of this study was the investigation of the relationship between Iranian learners' sociocultural identity and their EFL learning proficiency.

A hypothesis about the relationship between EFL learners' sociocultural identity and their EFL proficiency level in terms of learning was formulated in that EFL learning in Iranian context was associated with learners' sociocultural identity in a way that the sociocultural identity influenced learning English proficiency.

Teaching and learning English as a foreign language in Islamic situation in Iranian context is completely challenging issues since aspects of foreign language culture and society are in sharp difference with those introduced by Islam, such as friendship, marriage, dating, ideology and etc. the Muslim language learners show little, if at all, orientation to learning those aspects of foreign language culture which are forbidden in their religion (Behtash et al, 2017). Though political issue as another effective factor has affected Iranian's identity, religion is still the more influential factor in Iranian identity. As Behtash et al, 2017 stated religion is linked to a person's self and social identity. Language is a part of identity, thus learner cannot isolate his/her cultural identity while learning.

Findings of this study confirmed this hypothesis. In another word, there is a relationship between Iranian learners' sociocultural identity and their EFL learning. In this chapter, the discussion is carried out about this relationship with connections of the findings in this study to previous research literature.

\section{Discussion of Findings}

Sociocultural Identity and Learning English Proficiency

Regarding the research question, the relationship between sociocultural identity profiles and the degree of EFL learning proficiency, findings demonstrated that there is a great 
and negative relationship between them. The results supported the $\mathrm{H} 1$ in that sociocultural identity was most salient in the level of English learning proficiency.

Findings of this study, regarding the role of sociocultural identity on the level of EFL learning, one aspect of their relationship, was in line with some theories and research in Iranian context and other countries. Different aspects of identity were investigated as related to EFL learning in the Iranian context. Behtash et al (2017) investigated the impact of religious identity on EFL learning. Bazrafshan (2015) conducted a study about cultural identity and its effect on EFL pronunciation learning. Tavakoli et al (2014) investigated the influence of ego identity on EFL learning. However, in the present study sociocultural identity was considered. And the result proved findings of these previous studies.

This view was in line with second language learning theory (Peirce, 1995) and Sociocultural Theory (Donato \& McCormick, 1994). For example, Norton (2013) considered the investment of language as the complex relationship between language learner's identity and language learning. She argued that social power structures influence language learning opportunities and immigrants' investment in language learning.

According to Sociocultural Theory, social interaction and cultural foundations (e.g. schools, \& classroom) play an important role in an individual's school success and mental development. In contrast, the finding of the present study is in conflict with the result of Razmjoo (2010) since he found no significant relationship between language achievement and the learners' identity.

There were many studies around the globe regarding the role of different aspects of identity in second or foreign language learning as well as Iranian context. Interestingly, findings of most of them were proved by this research. Conversely, most of them have been taken place in English speaking countries and examined the relationship or impact of learners' on their English as a second language learning (Altugan, 2015). For Example, Parks (2000) in her research in ESP in Canada found that learners' identities had a significant influence on their investment, visions, and attitudes toward the same task.

However, there were some others in non - English speaking countries that investigated the relationship or impact of learners' identity on English as a foreign language learning. (e.g. Tran, 2007). If EFL student's identity degree is weak enough, it shows that $\mathrm{s} / \mathrm{he}$ wants to identify himself or herself as English, and English ability is important for him/her to achieve this goal. Therefore, most likely, s/he would like to devote time, energy, and money in learning English. As the other side of the same coin, if an Iranian student wants to identify himself or herself as Iranian with the high level of identity degree, English ability becomes unimportant for him/her. They will not welcome English language and identity to change their own. Thus, it is understandable s/he would not like to invest time, in learning English, although nearly most of the students who participated in privet institutes are willing to learn English for any reason. In that study, Iranian students' learning English was found to be affected by their nearly high level of 
sociocultural identity. Consequently, this finding can be helpful for teachers and instructors to consider the students level of identity and their attitude towards English, in teaching procedures. Teachers with modifying some pictures and sentences and matching them with learners' sociocultural identity, can teach them new language with less changes in learners' identity.

Moreover, students with an understanding of their level of identity can manage their energy and time in learning.

\section{Limitations of the Present Study}

The current study, like other research, was not out of limitations. The first limitation of the study was the problem of generalizability due to the following reasons:

1) The sample was selected from English students in private institutes, the results cannot be generalized to other students in public schools.

2) The selection of intermediate and advanced was a limitation of this study. The result cannot be generalized to other levels

3) Another reason can be considered for this study was that participants were selected from the institutes of two cities of Zanjan province, Iran. English learners in other cities of Zanjan province and other Provinces might have different responses. Thus the result might be affected and cannot be generalized.

A second limitation was that in the current study other influential factors on a language learning was not investigated. The result of the study might be the effect of these factors rather than identity.

The third limitation of this study was about the process of measuring of identity. Identity is a complex issue with different aspects, such as ethnic, religious, social, ego, cultural, etc. The aspects of identity are related to each other. In the present research, sociocultural identity was considered. However, one's sociocultural identity is not separated from his/her other aspects of identity. All of these factors influence one's identity. To understand a real degree of an individual's sociocultural identity all influential factors must be considered. However, the researcher failed to include all aspects.

Finally the time for answering the questionnaires for data gathering was limitation. Participants' short time in an institute did not allow them to answer the questionnaires carefully.

\section{CONCLUSION}

The main purpose of the present study was the study of the relationship between Iranian learners' sociocultural identity and the level of their EFL learning. Accordingly, findings of this study suggested that there is a negative significant relationship between sociocultural identity and EFL learning in the Iranian context. The higher and stronger the identity of learners, the less EFL learning proficiency will achieve. Statistical analysis findings of this study further have declared the mechanism of this relationship: EFL learners' sociocultural identity applies influence directly to their learning language. 
Language and sociocultural identity are components of each other, dependable and inseparable. Language, actually, both reflects and affects an individual's worldview, considering as a sort of road map to how one understands, interprets, thinks about, and expresses one's point of view of the world.

Moreover, in a linguistic view, language learners cannot completely isolate themselves from their cultural context. The background knowledge source constructed in their home society is used to understand the meaning of linguistic information of the target language (Hinkel, 1999; Tseng, 2002).

To sum up, in this study researcher found that there is a great deal of relationship between students' identity and their EFL learning process. Students' identity plays an important role in learning a new language learning with a new identity. The more strong identity of students, the more limitative impact on their EFL learning. As Greene (1986) stated, education, in general, is an essential part of socialization and is directly related to beliefs, interests, and ideologies. Thus education or learning can be affected by or affect other parts of socialization.

\section{Suggestions for Further Research}

The term of foreign language learning is a very complex issue that affects and is affected by different factors. (e.g. motivation, identity, culture, politics, age, etc.). There have been some studies in these fields. Further study can be done to show the influence of different factors on EFL learning and identity formation. Identity is a complex issue with different aspects; therefore, further studies can investigate the influence of different aspects of identity on the different situation and influential factors on identity formation.

\section{REFERENCES}

Achugar, M., \& Carpenter, B. D. (2018). Critical SFL Praxis Principles in English Language Arts Education: Engaging Pre-service Teachers in Reflective Practice. In Bilingual Learners and Social Equity (pp. 91-108). Springer, Cham.

Altugan, A. S. (2015). The Effect of Cultural Identity on Learning. Procedia- Social and Behavioral Sciences, 190, 455-458.

Bazrafshan, M. (2015). Cultural identity and attitudes: Iranian EFL context. bazrafshan1. pdf on 20.04.2017 http://semanticsarchive.net/Archive/mJiZDE2Y/

Behtash, I., Hashemi, S. \& Farokhipour, S. (2017). Influence of Religious Identity on a Foreign Language Learning: A Case of Iranian EFL Learners. International Journal of English Language \& Translation Studies. 5(2), 16-20

Cheek, J. M., \& Briggs, S. R. (2013). Aspects of Identity Questionnaire (AIQ-IV). Measurement Instrument Database for the Social Science.

Danaeifard, H., Khaef Elahi, A., \& Hosseini, S.M. (2011). Abating the promotion of knowledge sharing in the light of organizational citizenship behavior (Case study: Department of Housing and Urban Development and the Ministry of Roads and Transportation) "Public Administration Research, Year IV, No. XIV, pp. 84-63. 
Dávila, L. T. (2017). Ecologies of Heritage Language Learning in a Multilingual Swedish School. Journal of Language, Identity \& Education, 16(6), 395-407. https://doi.org/10.1080/15348458.2017.1385025

Donato, R., \& McCormick, D. (1994). A sociocultural Perspective on Language Learning Strategies: The Role of Mediation. The Modern Language Journal, 78(4), 453-464. DOI: 10.1111/j.1540-4781.1994.tb02063.x

Greene, M. (1986). In Search of a Critical Pedagogy. Harvard Educational Review, 56(4), 427-442. https://doi.org/10.17763/haer.56.4.010756lh36u16213

Grey, S., \& van Hell, J. G. (2017). Foreign-accented Speaker Identity Affects Neural Correlates of Language Comprehension. Journal of Neurolinguistics, 42, 93-108. https://doi.org/10.1016/j.jneuroling.2016.12.001

Hinkel, E. (1999). (Ed.). Culture in second language teaching and learning. Cambridge, UK: Cambridge University Press.

KhodayariFard, M. (2003). The Effectiveness of Cognitive Behaviour Therapy Combined with Pharmacological Treatment in Treatment of Schizophrenia (case study).

Machado-Casas, M. (2012). Pedagogías del camaleón/Pedagogies of the chameleon: Identity and Strategies of Survival for Transnational Indigenous. The Urban Review, 44 (5), 534-550 https://doi.org/10.1007/s11256-012-0206-5

Miller, A. L., Berlo, J. C., Wolf, B. J., \& Roberts, J. L. (2018). American Encounters: Art, History, and Cultural Identity. https://openscholarship.wustl.edu/books/39

Moser, K., Zhu, D., Nguyen, H., \& Williams, E. (2018). Teaching English Language Learners: A Mainstream Response to Rural Teacher Preparation. International Journal of Teacher Education and Professional Development (IJTEPD), 1(1), 58-75. DOI: 10.4018/IJTEPD.2018010105

Mostafaei Alaei, M., \& Ghamari, M. R. (2013). EFL learning, EFL motivation types, and national identity: In conflict or in coalition. Issues in Language Teaching, 2(2), 85111.

Norton, B. (2013). Identity and language learning: Extending the conversation. Multilingual matters

Orsini-Jones, M., \& Lee, F. (2018). Emerging Online Politeness Patterns. In Intercultural Communicative Competence for Global Citizenship (pp. 63-91). Palgrave Macmillan, London.

Pan, L., \& Block, D. (2011). English as a "global language" in China: An Investigation into Learners' and Teachers' Language Beliefs. System, 39(3), 391-402.. https://doi.org/10.1016/j.system.2011.07.011 
Parks, S. (2000). Same Task, Different Activities: Issues of Investment Identity, and Use of Strategy. TESL Canada Journal, 17(2), 21-28 DOI: https://doi.org/10.18806/tesl.v17i2.890

Peirce, B. N. (1995). Social Identity, Investment, and Language Learning. TESOL Quarterly, 29(1), 9-31. DOI: 10.2307/3587803

Razmjoo, S.A, 2010. Developing a Textbook Evaluation Scheme for the Expanding Circle. Iranian Journal of Applied Language Studies, 2(1): 121-136.

Richards, J. C., \& Schmidt, R. W. (2013). Longman dictionary of language teaching and applied linguistics. Routledge.

Tavakoli, Z, Rakhshanderoo, F, Izadpanah, M \& Moradi, M (2014). Ego Identity Types and Language Proficiency of Iranian EFL Learners. Procedia - Social and Behavioral Sciences 98: 1885 - 1894. https://doi.org/10.1016/j.sbspro.2014.03.619

Tran, L. (2007). Learners' Motivation and Identity in the Vietnamese EFL Writing Classroom. English Teaching, 6(1), 151-163.

Tseng, Y. -H. (2002). A lesson in culture. ELT Journal, 56(1), 11-21

Ward, C., \& Rana-Deuba, A. (1999). Acculturation and Adaptation Revisited. Journal of Cross-cultural Psychology, 30(4), 422-442. https://doi.org/10.1177/0022022199030004003

White, K., Stackhouse, M., \& Argo, J. J. (2018). When Social Identity Threat Leads to the Selection of Identity-reinforcing Options: The Role of Public SelfAwareness. Organizational Behavior and Human Decision Processes, 144, 60-73. https://doi.org/10.1016/j.obhdp.2017.09.007

Yuen, A. H., \& Hew, T. K. (2018). Information and Communication Technology in Educational Policies in the Asian Region. Handbook of Information Technology in Primary and Secondary Education, 1-20. doi.org/10.1007/978-3-319-53803-7_86-1

Zare-ee, A., \& Asgari Matin, S. (2014). The Relationship Between EFL Learners' SelfIdentity Changes, Motivation Types, and EFL Proficiency. Iranian Journal of Applied Language Studies, 6(2), 141-178.

Zeinivand, T., Azizifar, A., \& Gowhary, H. (2015). The relationship Between Attitude and Speaking Proficiency of Iranian EFL Learners: The case of Darrehshehr City. Procedia-Social and Behavioral Sciences, 199, 240-247. https://doi.org/10.1016/j.sbspro.2015.07.512

Zhou, M. (2016). Chinese University Students' Acceptance of MOOCs: A selfDetermination Perspective. Computers \& Education, 92, 194-203. DOI: $10.1348 / 0007099041552314$ 